\title{
Comparison of Field and Laboratory Result of Fiber Reinforced Shotcrete Application
}

\author{
Gökhan Külekçi $i^{\text {* }}$ \\ ${ }^{1}$ Department of Mining Engineering, Faculty of Engineering and Natural Sciences, Gumushane University, 29100 Gumushane, Turkey \\ * Corresponding author, e-mail: gkulekci@gumushane.edu.tr
}

Received: 17 August 2020, Accepted: 26 December 2020, Published online: 07 January 2021

\begin{abstract}
Synthetic fibers, which have become one of the main components of shotcrete, have been studied by many researchers in the laboratory environment. Unfortunately, the results obtained as a result of these researches are not suitable for underground chimneys due to the differences in ambient conditions and application differences. In this study, it is aimed to compare the results of the experiment samples prepared and kept in the laboratory with the mechanical properties of the shotcrete applied in underground conditions. For this purpose, keeping the slump and cement proportions constant, 35 cubic samples were prepared using 2 and 6 kg synthetic fiber for $1 \mathrm{~m}^{3}$ in the laboratory, and 30 cylinder samples and 6 plate samples were prepared for underground. While mechanical experiments were carried out on prepared cube and cylinder samples, the EFNARC plate test and freeze-thaw test were carried out on plate samples. It was observed that the set accelerator made a significant increase in resistance at the end of the 28 days and that the resistance of the samples prepared with polyester fibers in the laboratory environment were very high. As a result of the EFNARC panel tests performed, it was determined that the energy absorption of synthetic fibers increased with fiber amount. Thanks to this study, the energy absorption of the synthetic fiber used has been measured, and the reliability and practicality of the experiments carried out in the laboratory have been increased by evaluating the field conditions and laboratory conditions.
\end{abstract}

Keywords

fiber, freeze-thaw cycles, shotcrete, underground conditions

\section{Introduction}

Recently, the synthetic fibers whose utilization has increased in terms of the effect of strength and applicability in mining industry is involved in thermoplastics as material and is a considerably lightweight polymer [1-5]. They constitute the raw material of almost half of the plastics used in the daily life. From this point of view, it is possible to say that the synthetic fibers whose production is cheap are a plastic [6-9]. In mining and other industries, the most significant advantage of utilization of the polyester fiber-reinforcement shotcrete is to get under control the cracks occurred because of the plastic shrinkage in the first few hours after concrete casting [10-13]. This shrinkage is fundamentally a native result of evaporation and chemical reaction started between water and cement. The polyester fibers are no effective in comparison with the steel fibers on the mechanical strength of concrete. However, they give the energy absorption capability to concrete and are especially effective about plastic shrinkage. The polyester fibers are preferred against the shrinkage which is especially no very strong. The polyester fibrillas having different physical properties can be alternatively used to polyester fibers using as concrete admixture [13, 14].

Many studies were performed the utilization of fibrilla on the strength and durability of concrete [9], effect of the fibrilla length and dosage on the concrete strength and toughness [10,15-17], utilization of fibrilla on the improvement of interfacial properties of cementitious composites [11] and effect of fibrilla admixture on the mechanical properties of lightweight concretes [12].

In the fiber-reinforced shotcrete (SC) studies, wellknown beam and panel tests have been developed to determine the mechanical properties of $\mathrm{SC}$, to investigate the toughness behavior and energy absorption of fibers [18]. Panel tests are generally thought to better represent fiber behavior in SC $[10,11,19,20]$. Since panel tests are performed as a central point loading of a large square panel 
supported on four beams, panels testing is considered to be one of the most reliable test methods of post-cracking performance evaluation. Fiber-reinforced sample toughness is obtained by calculating the areas under the experimentally obtained load-deflection curves and is considered to be the ability of the fibers to absorb energy. Although this characterization effectively measures the post-cracking behavior of fiber-reinforced concrete, energy absorption is largely dependent on the size of the samples [21-25]. Panel-based performance evaluation is desirable because the panels cannot pass a combination of stress actions that reflect the concrete behavior closer than other mechanical tests in the laboratory.

Ultrasonic pulse velocity (UPV) test, a non-destructive, reliable, cheap and easy method to apply, is one of the most popular techniques to determine the geotechnical properties of rock or cement based materials in both field and laboratory conditions [13]. In this scope, the ultrasonic tests were subjected to measure the s-wave velocity of fibers used and backfills. In the scope of the study, in a shotcrete application at an active underground mine business, the uniaxial compressive strengths and ultrasonic pulse velocities of samples taken from the mixer nozzle, samples prepared in the laboratory with synthetic fiber and cylinder samples taken from the application site was examined by comparing.

\section{Materials and method}

\subsection{Materials}

In this study, different amount of polyester synthetic fiber was used. The effect of utilization of synthetic fibers on the strength of shotcrete used as main and auxiliary support equipment in underground were investigated and the reasons of this effect were examined. In this study, the cylinder samples taken from the surface where the shotcrete was applied underground were used.

Also, cube and slab samples prepared using underground mixing ratios were studied. While mechanical tests were performed on prepared cube and cylinder samples, EFNARC plate test and freeze-thaw test were performed on plate samples. The reasons of the differences in mechanical properties on the samples prepared in the same mixture ratios in the underground and laboratory were examined (Table 1).

\subsubsection{Aggregates}

The amount and properties of fine material in aggregates used in shotcrete production are directly influenced the quality of shotcrete.
The presence of a particular amount of filler provides a certain of contribution for the shotcrete quality because the filler material in shotcrete fills the voids. However, this material having no binding characteristic causes to occur several quality problems in shotcrete when increasing the amount of filler. For this purpose, $600 \mathrm{~g}$ of $0-4 \mathrm{~mm}$ and $900 \mathrm{~g}$ of $4-8 \mathrm{~mm}$ of aggregates were taken from aggregate stockpile according to sampling method and ratio of 1.5. The amount of these aggregate samples was then reduced to $219.4 \mathrm{~g}$ according to sampling reduction method and the sieve analysis of sample was done.

\subsubsection{Cement}

Ordinary Portland cement (CEM I 42.5R) provided from Akçansa cement plant was used as the binder in experimental study. The same binder type has also been used in pilot mine plant. The chemical composition, physical and mineralogical properties of the cement are summarized in Table 2.

\subsubsection{Synthetic fiber}

The fiber is a raw material that it is obtained from natural resources or is produced by man-made and it has a length, pliableness, flexibility and durability properties. In general, there are two types of fibers such as natural and

\begin{tabular}{lc}
\multicolumn{2}{c}{ Table $\mathbf{1}$ The mixture design for shotcrete of $1.0 \mathrm{~m}^{3}$} \\
\hline Material & Weight $(\mathrm{kg})$ \\
\hline Cement & 450 \\
Water & 205 \\
Aggregate sizes $(\mathrm{mm})$ & \\
$0-4$ & 900 \\
$4-8$ & 600 \\
Synthetic fiber $(54 \mathrm{~mm})$ & 6 \\
Set-accelerator & 45 \\
Plasticizer & 5 \\
\hline
\end{tabular}

Table 2 Chemical, physical and mineralogical properties of CEM I $42.5 \mathrm{R}$

\begin{tabular}{lccc}
\hline \multicolumn{2}{c}{ Chemical composition (\%) } & \multicolumn{2}{c}{ Mineralogical composition } \\
\hline $\mathrm{Al}_{2} \mathrm{O}_{3}+\mathrm{SiO}_{2}$ & 25.38 & $\mathrm{C}_{3} \mathrm{~S}$ & 58.44 \\
$\mathrm{Fe}_{2} \mathrm{O}_{3}$ & 3.67 & $\mathrm{C}_{2} \mathrm{~S}$ & 14.95 \\
$\mathrm{SO}_{3}+\mathrm{MgO}$ & 4.32 & $\mathrm{C}_{3} \mathrm{~A}$ & 6.54 \\
$\mathrm{CaO}$ & 65.27 & $\mathrm{C}_{4} \mathrm{AF}$ & 11.16 \\
$\mathrm{Free} \mathrm{CaO}$ & 1.19 & & \\
Loss on ignition & 2.1 & \\
\multicolumn{4}{l}{} \\
Specific gravity $\left(\mathrm{g} / \mathrm{cm}^{3}\right)$ & Physical properties \\
\hline
\end{tabular}


artificial fibers. Animal and plant fibers are natural fiber. The artificial fibers are materials that specially developed to have certain properties and produced for this aim. There are many types of fibers with regards to usage area and properties of fibers. It is possible to classify these fibers in different forms. Meyco Fib SP 540 brand synthetic fiber was used in the study (Fig. 1).

Mixtures were prepared using 2 and $6 \mathrm{~kg}$ per $1 \mathrm{~m}^{3}$ of cylindrical and cube samples prepared in the laboratory. Cores taken from the application area were used $6 \mathrm{~kg}$ for $1 \mathrm{~m}^{3}$ Table 3 .

\subsection{Method}

In this study, 30 cylindrical samples, 6 plaque samples and 35 cubic samples were prepared in the laboratory in order to investigate and compare the mechanical properties of synthetic fibers in underground and laboratory conditions (Table 4).

\subsubsection{Production of shotcrete}

In this study, samples and supplied from underground conditions were coded to determine the properties of 6 different shotcrete produced. The coding process is named

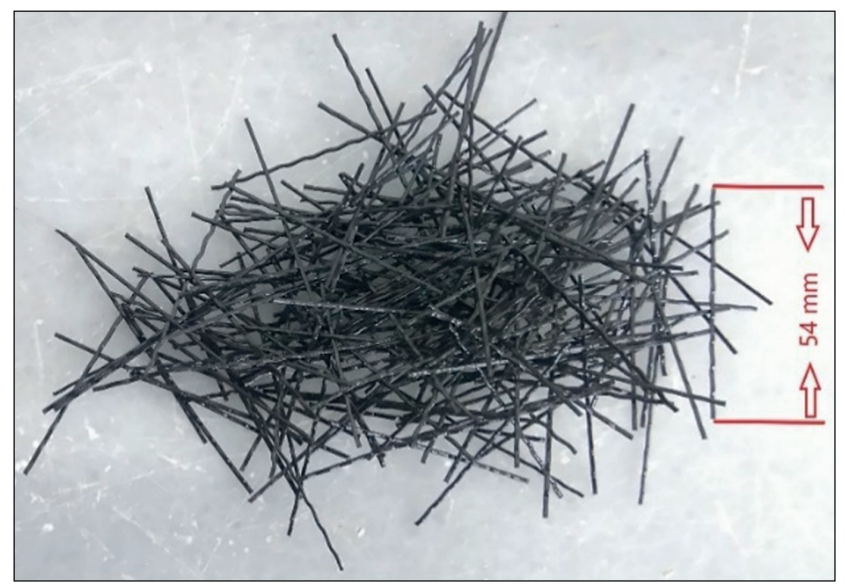

Fig. 1 Synthetic fibers used in the study according to, for example, the properties of the place of receipt, the content of fiber it contains and whether the sample contains an accelerating admixture (Table 5).

\subsubsection{Core sampling from underground and measurement of unconfined compressive strength}

The shotcrete practiced in pilot mine is carried out for ground support in underground and the strength beyond the 14-day strength of $\geq 20 \mathrm{MPa}$ is desired depend on formation structure. To understand if this strength can be achieved or not and to improve the strength if it is not obtained, a total of 40 cylindrical core samples with $54 \mathrm{~mm}$ of diameter (13 core samples of 14 days of curing periods and 27 core samples of 28 days) were taken from application field with portable core drill (Fig. 2).

Table 3 The technical properties of fibers used

\begin{tabular}{lc}
\hline Characteristic & Material properties \\
\hline Raw material & Polyester \\
Shape & Wavy \\
Length & $54 \mathrm{~mm}$ \\
Diameter & $0.8 \mathrm{~mm}$ \\
Number of fibers & 220.000 piece per $\mathrm{kg}$ \\
Density & $0.92 \mathrm{~g} / \mathrm{cm}^{3}$ \\
Melting point & $150-170{ }^{\circ} \mathrm{C}$ \\
Burning point & $412{ }^{\circ} \mathrm{C}$ \\
Water sorption & $0($ None) \\
Acid / Alkaline resistance & Excellent \\
Color & Black \\
\hline
\end{tabular}

Table 4 Sample quantity and dimensions used in the study

\begin{tabular}{lcccc}
\hline $\begin{array}{l}\text { Sample } \\
\text { collection }\end{array}$ & Shape of sample & $\begin{array}{c}\text { Size of } \\
\text { sample }(\mathrm{cm})\end{array}$ & $\begin{array}{c}\text { Number of } \\
\text { samples }\end{array}$ & $\begin{array}{c}\text { Curing } \\
\text { time }\end{array}$ \\
\hline Under & Plaque & $60 \times 60 \times 10$ & 6 & 28 \\
ground & $\begin{array}{c}\text { Cylinder coring } \\
\text { from plaque }\end{array}$ & $10 \times 10$ & 18 & 28 \\
& $\begin{array}{c}\text { Cylindrical } \\
\text { Lab. }\end{array}$ & $10 \times 20$ & 30 & $7-14-28$ \\
\hline & Cubic & $15 \times 15 \times 15$ & 35 & $7-14-28$ \\
\hline
\end{tabular}

Table 5 Name codes of the samples

\begin{tabular}{|c|c|c|c|c|c|c|}
\hline Sample code & 6UCA & $6 \mathrm{UC}$ & 6LCA & $2 \mathrm{LCA}$ & 2LPA & 6LPA \\
\hline Received sample / Prepared location & Underground & Underground & Laboratory & Laboratory & Laboratory & Laboratory \\
\hline Fiber type filled with numen & Polipropilen & Polipropilen & Polipropilen & Copolymer & & \\
\hline shape of samples & Cylinder & Cube & Cube & Cube & Plaque & Plaque \\
\hline The content of fiber & 6 & 6 & 6 & 2 & 2 & 6 \\
\hline Set accelerating admixture & There is & - & There is & There is & There is & There is \\
\hline
\end{tabular}

PUHA: Polipropilen Underground High Admixture, PU: Polipropilen Underground, PLHA: Polipropilen Laboratory High Admixture,

KLHA: Copolymer Laboratory High Admixture 


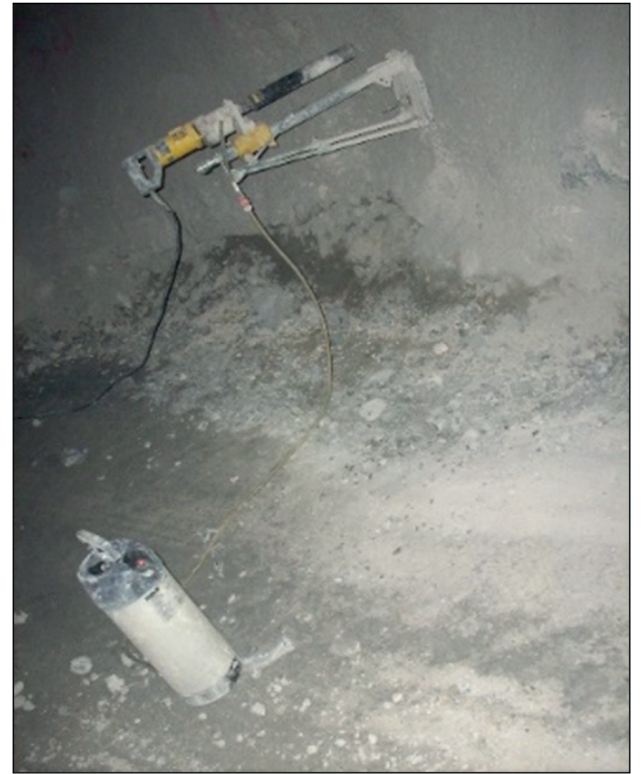

Fig. 2 The core sampling from shotcrete practiced in underground

First, the bottom and top surfaces of core samples taken from application field were made smooth and flat and they were prepared measuring the lengths of samples via ruler in a way to ensure the suitable height to diameter ratio according to standards. The prepared cylinder samples were uniaxial compressive strength tests in accordance with ISRM 1918 standards.

\subsubsection{Preparation of cubic sample in laboratory and measurement of unconfined compressive strength}

In the shotcrete mixture applied, it is very important that each material is used in the same amount with the amount specified in the application. The change of the amount and type of material may be affected the strength and setting properties of shotcrete. Besides, the effect of mixer where the shotcrete is mixed is important for the strength of shotcrete. In automatic computer system, the mixer blending time of concrete plant is minimum 90 second for the shotcrete. When the blending operation does less time than 90 second, the aggregate and cement will not homogenously mix and the strength of shotcrete will reduce. Because of these reasons, a total of 9 samples prepared at the same mixture properties in laboratory conditions (Fig. 3) and 15 shotcrete samples prepared with the mixture obtained from mixer were poured into the $15 \mathrm{~cm}$ cubic mold to confirm the material used, the amount of material and blending time. When the each one-third of mold was filled, the compacting operation was carried out making 25 tamping. The shotcrete samples were left in mold at a day for hardening and then, they were subjected to the curing operation during the predetermined curing periods.
The correction coefficient was used via a formula recommended by Ercikd1 et al. [26] in order to compare the unconfined compressive strength values of cylindrical samples taken from pilot mine plant and cubic shotcrete samples prepared in laboratory and mixer [13].

\subsubsection{Measurement of UPV}

First, the samples were removed from mold and the bottom and top surfaces of samples were made smooth and flat for the UPV test of a total of 240 fiber reinforced shotcrete samples (the cylindrical and cubic samples taken from mine plant and the cubic samples prepared in laboratory) (Fig. 4(a)). The length of $150 \mathrm{~mm}$ cubic samples removed from mold and the cylindrical samples taken from underground according to diameter to height ratio of $1 / 2$ were recorded measuring within caliper gage having an accuracy of $0.1 \mathrm{~mm}$. Then, a thin film of vaseline was applied to the surface of the transducers (transmitter and receiver) in order to ensure full contact and to eliminate the air pocket between transducers and the test medium. At the predetermined curing periods (7, 14, 28

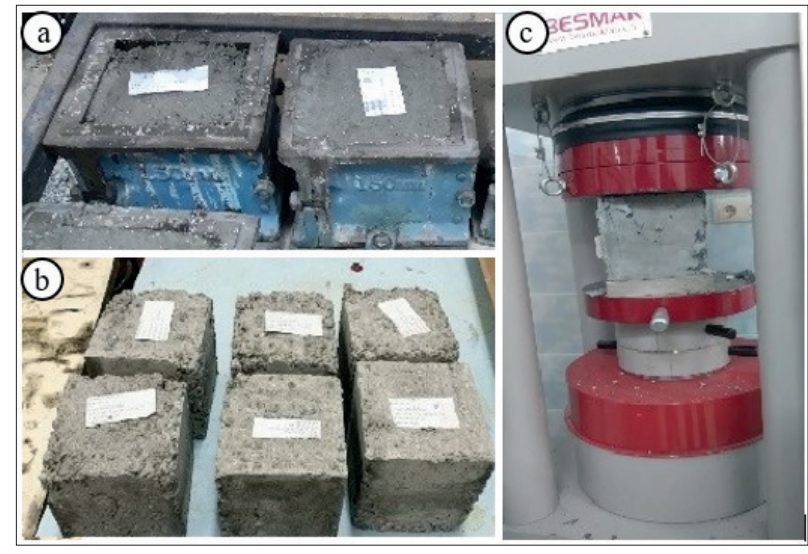

Fig. 3 (a, b) The cubic shotcrete samples prepared in laboratory and (c) unconfined compressive strength test of samples

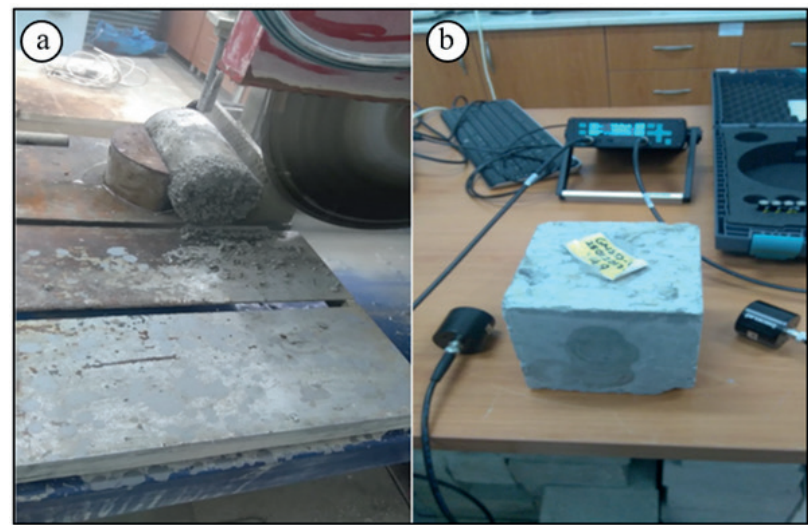

Fig. 4 (a) The cylindrical samples taken in-situ, (b) Ultrasonic measurements of cup samples 
and 56 days), the shotcrete samples were subjected to the UPV tests with Pundit $\mathrm{Lab}^{+}$model equipment that measures the time of propagation of ultrasound pulses with a precision of $0.1 \mu \mathrm{s}$ and $24-500 \mathrm{kHz}$ of signal frequency according to [14] (Fig. 4(b)).

\subsubsection{Production of panel samples and determination of energy absorption capacity}

The use of fiber in shotcrete used for fortification in underground and surface mining is quite common. Fibrous shotcrete has differences in terms of mechanical and physical properties compared to fiberless shotcrete. One of the most important reasons for using shotcrete for fortification is the toughness, and the other one is its ability to absorb energy. Different mechanical properties such as crack resistance, ductility, flexibility, impact resistance are associated with energy-absorbing capacity. This property, which is also called toughness, is defined with the area under the load-deflection curve. Poured panels: At the end of the 28-day curing period, the poured panel samples were broken under the press to obtain the toughness values of the fibers and the load-deflection curves were obtained (Fig. 5(a)).

\subsubsection{Coring from panel samples and freeze-thaw test}

Freeze-thaw resistance is examined to see how concrete can be affected by sudden heat changes. The freeze-thaw test was applied to a total of 18 cylinders of $10 \times 10 \mathrm{~cm}$ dimensions taken from $60 \times 60 \times 10 \mathrm{~cm}$ panels with a concrete core machine (Fig. 5(b)). The cylindrical samples were placed in sample cells with an internal diameter of $10.6 \mathrm{~cm}$ made of a material, which is heat-conducting and
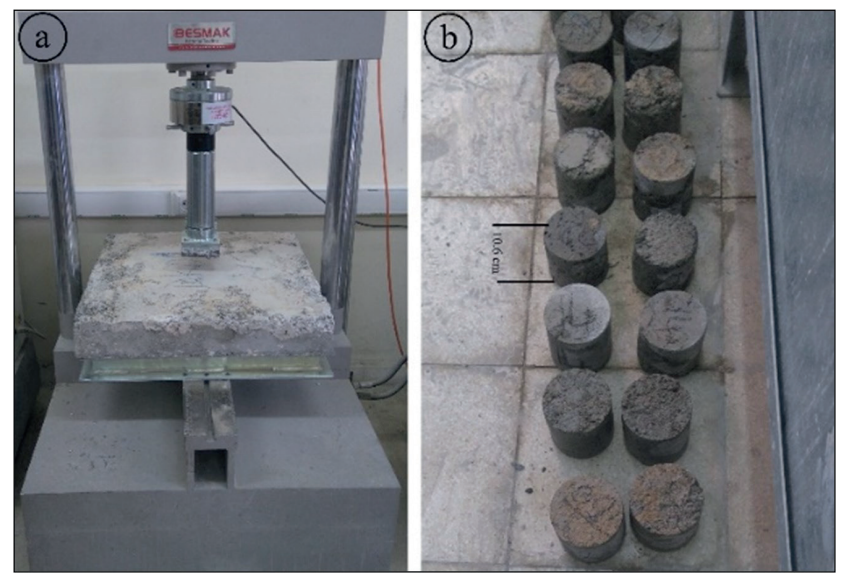

Fig. 5 (a) Determination of energy absorption capacity of panel samples, (b) Freeze-thaw test in panel samples non-corrosive to water, in accordance with the principles set out in ASTM C666 Procedure A [27]. Cylinder samples placed in the appropriate containers were filled with water and placed in the freeze-thaw equipment and expected to complete the cycle time. Basic horizontal frequency changes, mass changes of concrete samples were recorded in every 30 freeze-thaw cycles.

A freeze-thaw cycle occurs in the following order;

a) The temperature is reduced from $(20 \pm 3)^{\circ} \mathrm{C}$ to 0 (zero) ${ }^{\circ} \mathrm{C}$ per minute $(150 \pm 30)$ and kept at 0 (zero) ${ }^{\circ} \mathrm{C}$ for $(210 \pm 30)$ minutes.

b) Temperature is decreased from 0 (zero) ${ }^{\circ} \mathrm{C}$ $(-17.5 \pm 2.5)^{\circ} \mathrm{C}$ per minute $(180 \pm 30)$ to $(-17.5 \pm 2.5)^{\circ} \mathrm{C}$ for at least 240 minutes. It is kept in C. Metal cans should be stored at $(-17.5 \pm 2.5)^{\circ} \mathrm{C}$ if the test needs to be interrupted during the freezing cycle or during manual control for reasons such as holidays. The maximum period that the experiment can be suspended is 72 hours.

c) Air temperature should not be allowed to fall below $-22^{\circ} \mathrm{C}$ at any stage.

\section{Results and discussion}

In this study, the material properties used for the first time were examined. The used aggregate was first sieved using the dry sieving method on-site where it was found (in the mine) and then it was brought to the laboratory where it was sieved using the dry and wet sieving methods. Based on the results of the sieve analysis, in the laboratory, 5.36\% fine material $(-0.063 \mathrm{~mm})$ was found as a result of the wet sieving and $19 \%$ as a result of the dry sieving. In the on-site dry sieving result, it was determined that the aggregate contained about $13 \%$ of fine material (Fig. 6).

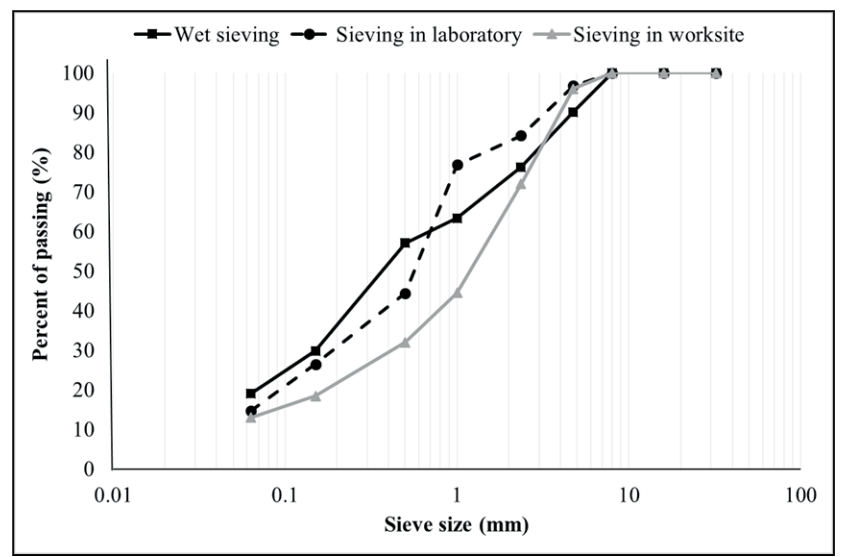

Fig. 6 Aggregate sieve analysis 


\subsection{Differences in underground and laboratory samples} In this study, uniaxial compressive strengths of 40 core samples (6UCA) taken from the shotcrete that is sprayed to the mine walls for fortification with Meyko Kobra spraying machine under the ground were compared with uniaxial compressive strengths of 28 samples (6LCA) prepared in the laboratory with the same prescription. There is a certain difference in 6LCA strength in all curing periods in the results of the cracking. At the end of the day, 6LCA strengths were $42.53 \%$ more, and this difference decreased to $15.69 \%$ after 28 days (Fig. 7). The main reason for the high strength of the samples prepared in the laboratory environment is that the curing conditions are standard and the size of the aggregate was small when brought to the lab. The results of the sieve analysis support the decrease in aggregate size. In the literature studies, it has been shown that as the fine grain size increases, the strength will increase for a certain period and rate, and this is due to the filler effect. It can also be explained that the high strength in the laboratory environment is due to the changing humidity, temperature, and pressure difference caused by spraying in the underground.

\subsection{Effect of set accelerator on strength}

The uniaxial compressive strength of 15 cube samples taken from the mixer nozzle (without the set accelerator, 6UC) and during underground spraying (with the set accelerator, 6UCA) were measured the accuracy of the prescription used in the mine worked and to see the effect of the set accelerator on strength. It was found in strength results taken in the short-term (7, 14, 28 days) that 6UCA strength $7^{\text {th }}$ and $14^{\text {th }}$ days. It was seen that they were low in the 6UC strength at the end of the day, and they exceed PUHA strength at the end of $28^{\text {th }}$ day (Fig. 8).

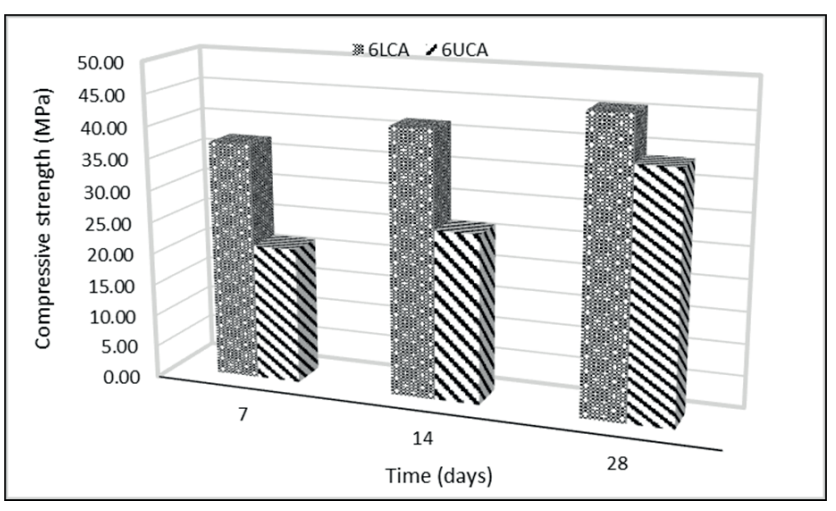

Fig. 7 The relationship between underground and laboratory applications
Set accelerators have different effects depending on the dosage rate of the reinforcement and the chemistry of the cement, and its chemistry. Some of the commercial reinforcements contain calcium chloride. Many accelerators reduce the 14-day strength by $25-40 \%$ depending on the harmony of the cement and the accelerator. Accelerators can reduce the freezing strength of spraying. Some of them can be very caustic and, therefore, dangerous in terms of safety. For these reasons and because they are expensive, accelerators should only be used in a minimum amount and, if necessary, to achieve the desired result [13].

\subsection{Effect of fiber content on mechanical properties of plaque samples}

By using the same mixture rates used in sample plant, 6 fiber reinforced, 3 and $6 \mathrm{~kg}$ panel samples with $60 \times 60 \times 10 \mathrm{~cm}$ size were prepared for $1 \mathrm{~m}^{3}$ mixture. EFNARC panel test was performed on the prepared panels and their energy absorption capacities were measured. Moreover, the freezing and thawing relationship of $10 \times 10 \mathrm{~cm}$ core samples taken from the panels was investigated.

The panel samples were broken after the highest load and the test was terminated. Fiber-free and fiber-containing panels were regularly split into 4 parts as expected (Fig. 9) $[16,17,20]$.

\subsubsection{Effect of fiber amount on energy absorption capacity}

Energy absorption capacity of 2 (2LPA) and 6 (6LPA) kg polyester fibers which were added to a $1 \mathrm{~m}^{3}$ concrete mixture, and reference panel samples were compared. It is seen that the toughness index increases with fiber ratio. The toughness energy of 6LPA coded panels with $6 \mathrm{~kg}$ polyester fiber

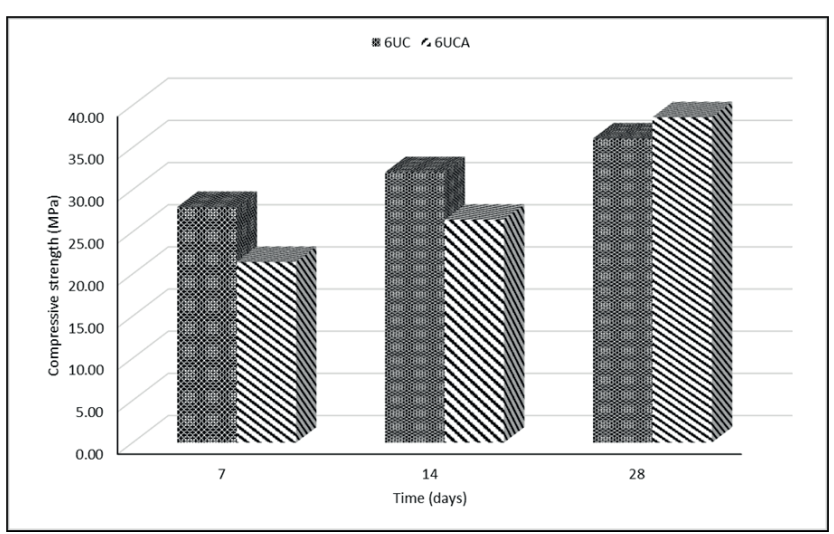

Fig. 8 The effect of the setting accelerator on shotcrete underground 
reinforcement was found to be 415.51 joules, and the energy absorption capacity of 2LPA coded panels was measured as 243.42 joules. The amount of energy obtained when the polyester fiber amount used in $1 \mathrm{~m}^{3}$ material was increased 3 times, was increased by $71 \%$ (Fig. 10).

The load carrying values of the fiber-free reference (ref.) samples were found to be very low compared to fiber-containing panels. The deflection value was found to be $4.5 \mathrm{~mm}$ and the total energy absorption capacity was found to be 22 joules.
In the panel tests, it was shown that as the amount of fiber increased, the force damping and deformation increased, and the energy absorption capacity increased (Fig. 11). There is also a certain increase in uniaxial compressive strength. It is also known that significant increases are obtained in ductility and toughness of fibrous concrete compared to concrete without fiber. In fibrous concrete, the factors affecting the concrete properties within the parameters entering the concrete composition are the slenderness ratio and the amount of fiber.

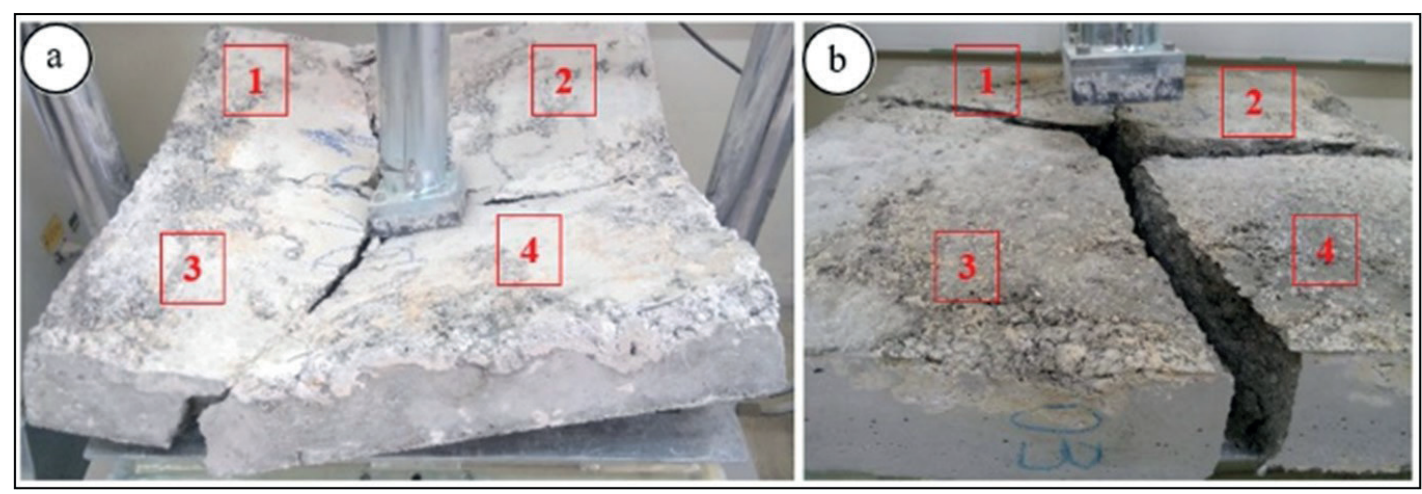

Fig. 9 Regular breakage of plates in 4 pieces, a) fiber-containing plaque, b) fiber-free reference plaque
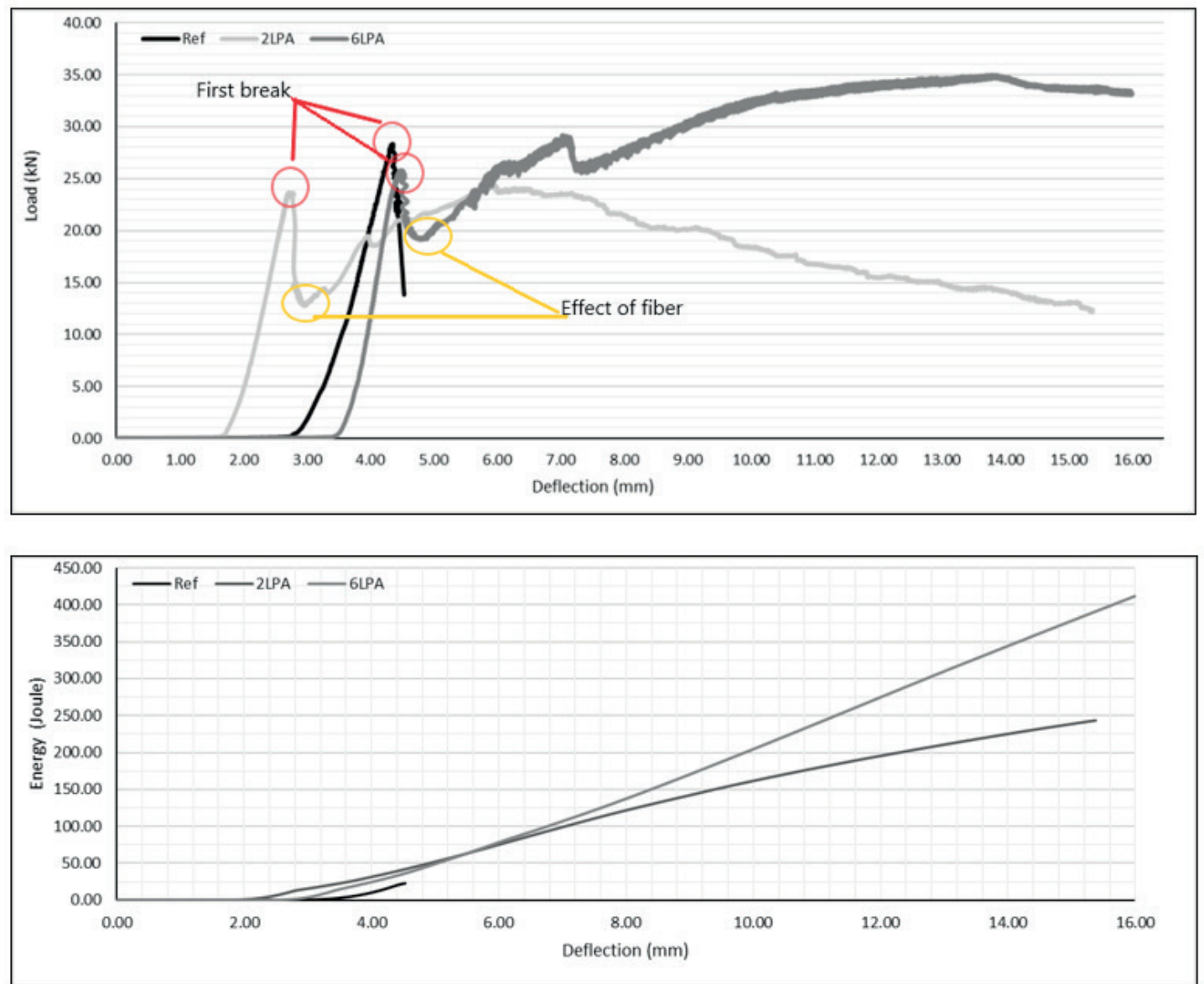

Fig. 10 Effect of polyester fiber amount on toughness energy 


\subsubsection{Effect of fiber content on the freeze-thaw cycle}

Cylinder samples taken from fibrous panel concrete were subjected to the freeze-thaw tests under appropriate conditions. The experiments were calculated as 360 cycles, but the samples came to a point that no measurements could be taken at the end of 240 cycles. The experiment was resumed for 240 cycles, and the $\mathrm{P}$ wave velocity and masses of the samples were measured once in every 30 cycles. The results of the experiment showed that the masses of the samples and the ultrasonic pulse velocity generally decreased after 240 cycles. As seen in Fig. 12, at the end of 240 cycles, there was a mass loss in concrete due to the effect of freezing and thawing. The maximum mass loss was referenced with $30.18 \%$, while the minimum weight loss was $3.66 \%$ on 6PLA.

In the freeze-thaw test, the ultrasonic sound pulse velocity rate was also reduced. UPV analysis could not be performed because of the deformation on the reference samples at the end of 150 cycles. As a result of UPV analysis performed on fiber-containing cores, the maximum UPV reduction was observed on the 2LPA samples containing the minimum amount of fiber (Fig. 13).

When the relationship between the amount of fiber and the freeze-thaw is analyzed in general, it was clearly revealed that the weight of the fiber decreased depending

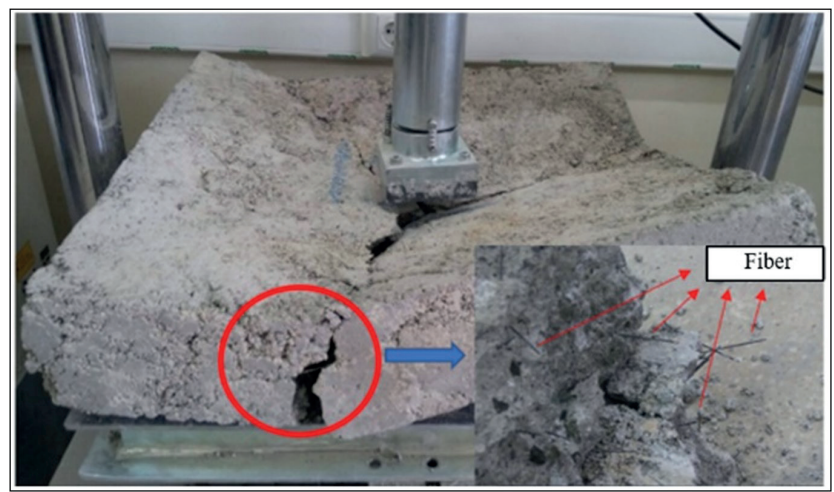

Fig. 11 Fibers prevent disintegration and increase flexibility

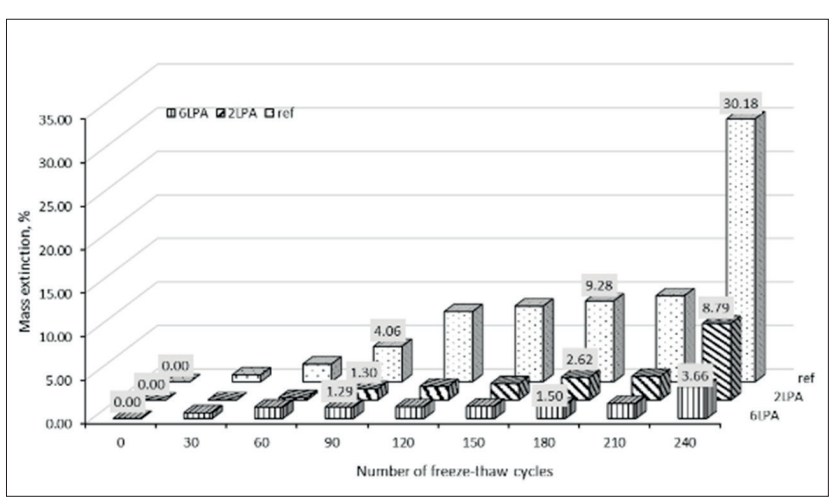

Fig. 12 Mass loss rates as a result of the freeze-thaw cycle on the fiber ratio, and the 6LPA samples containing excess fiber delayed the disintegration by holding the concrete mass of fibers. After the freeze-thaw test of fiber-containing concrete samples, $\mathrm{P}$-wave velocities were found to decrease; the reason for this is the increased micro-cracks and porosity. With the effect of freezing and thawing, the concrete pieces break but cannot be separated from the main mass through fibers. As a result of this phenomenon, capillary gaps are formed, and this greatly affects the pulse velocity.

\subsection{Effect of fiber amount on mechanical properties}

By using the Polyester synthetic fiber, which is used in the working area, samples were prepared in two different ratios $\left(2\right.$ and $\left.6 \mathrm{~kg} / \mathrm{m}^{3}\right)$. The uniaxial compressive strength difference and the ultrasonic pulse velocity were examined on the samples (Fig. 14).

It was determined that; at the end of 28 days, the strength of concrete samples produced using $6 \mathrm{~kg} / \mathrm{m}^{3}$ fiber (6LCA) is better than the strength of concrete samples with $2 \mathrm{~kg} / \mathrm{m}^{3}$ fiber reinforcement by $7.6 \%$. In the first measurements (day 7), 6LCA samples with $37.24 \mathrm{MPa}$ strength reached $45.75 \mathrm{MPa}$ strength after 28 days. Increase in pressure

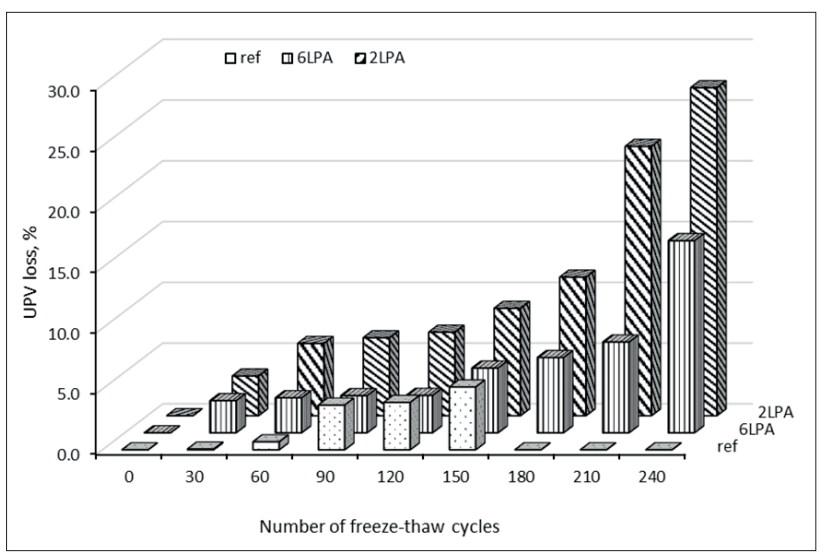

Fig. 13 UPV analysis results after freeze-thaw cycle

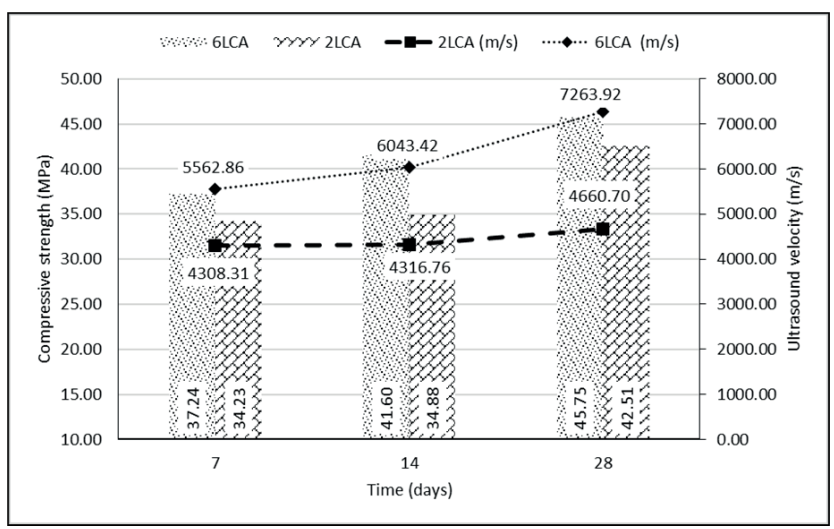

Fig. 14 Effect of fiber amount on mechanical properties 
strength with the increasing curing period is provided by filling the gaps between the aggregate grains of $\mathrm{C}-\mathrm{S}-\mathrm{H}$ gels formed by binder hydration and the increase in hardness of concrete samples. The most prominent feature of this is the increase in the UPV rates. In 6LCA samples, pulse velocity of $5.6 \mathrm{~km} / \mathrm{h}$ on the $7^{\text {th }}$ day became $7.3 \mathrm{~km} / \mathrm{h}$ at the end of 28 days and increased by $30.4 \%$. Moreover, consolidation of the concrete with its weight, drying, and evaporation of the water within may contribute to the development of hardening of the shotcrete sample [15].

\section{Conclusions}

In this study; the differences in surface and underground environment, the effect of the set accelerator, the effect of fiber amount on panel samples for the application of shotcrete application in the underground operating mine were investigated. Cube samples taken from mixer outlet, core samples were taken from the underground application, panel samples containing different amounts of fiber and core samples taken from these panels were mechanically tested and the results were examined in detail. In the literature, it is desired that the shotcrete should have a maximum of $15 \%$ of -63 micron material. An aggregate granulometry experiment was carried out in the field and in the laboratory. In the aggregate used in the shotcrete, $5.36 \%$ of material was found to be under -63 microns as a result of the wet sieving. As a result of the dry sieving conducted on-site, $13 \%$ fine material $(-0.063 \mathrm{~mm})$, and as a result of the dry sieving conducted in the laboratory, $19 \%$ fine material was found. These differences were due that the grains got worn while they were brought to the laboratory for the experiment and therefore thin grains increased. Additionally, the fact that the proportion of the fine material in the wet sieving is low indicates that the material has a clayey and silty structure, which can cause it to clump in the aqueous medium and behave like a coarse aggregate. Polyester fiber was used in the shotcrete applied in the mine. The strengths of the samples prepared with the same fiber in the laboratory were compared with those of the samples taken from the underground. As a result, the strength of the samples prepared in the laboratory was $7.1 \%$ more after 28 days. This may be due to many reasons. First of all, as the fine grain ratio increases to a certain extent, the effectiveness of binding will increase and the strength will increase. Thus, one reason could be the possibility that the fine aggregate amount of the utilized aggregate increased when brought to the laboratory and accordingly it created a filler effect by filling the gaps of the cement paste. The second reason could be explained by the possibility that the sensitivity of mixture preparation, compacting, sample storage and curing conditions may be higher in the laboratory environment. Strength tests were carried out in order to observe the impact of the set accelerator on the cube samples (6UC), which were taken from the mixer at the site where the shotcrete application was made and which did not contain the set accelerator, and the core samples (6UCA) containing the set accelerator from the underground application area. Since the set accelerators were applied at the moment of spraying from the mixer nozzle, the set accelerator was present in the cylinder samples taken from the application area. As a result of the experiments, it was determined that the set accelerator did not impact the strength after 7 and 14 days or impacted adversely, and that there was an increase in the strength by $6.5 \%$ at the end of 28 days. EFNARC panel test was performed on the prepared panels and the shotcrete energy absorption capacities were measured. In measurements, it was observed that samples prepared by adding $6 \mathrm{~kg} / \mathrm{m}^{3}$ fiber absorb $71 \%$ more energy compared to the panels prepared with $2 \mathrm{~kg} / \mathrm{m}^{3}$ fiber. Significant increases in ductility and toughness of fibrous concrete compared to fiberless concrete have also been demonstrated in literature. Freezing and thawing relationship of $10 \times 10 \mathrm{~cm}$ core samples taken on panels were investigated. Freeze-thaw tests could only be sustained for 240 cycles. The measurement results showed that the masses of the samples and the ultrasonic pulse velocities generally decreased. At the end of 240 cycles, with the effect of freezing and thawing, parts of the concrete broke and caused the mass loss. The highest loss was found in the reference samples which did not contain fiber, whereas the least loss was $3.66 \%$ in the samples with the highest fiber content. It has become clear that the fiber particles prevent the disintegration of mass. After the freeze-thaw test of fiber-containing concrete samples, P-wave velocities were found to decrease; the reason for this is the increased micro-cracks and porosity. With the effect of freezing and thawing, the concrete pieces break but cannot be separated from the main mass through fibers. As a result of this phenomenon, capillary gaps are formed, and this greatly affects the pulse velocity.

When the effect of fiber amount on mechanical properties was examined, it was found that strength of concrete samples produced using $6 \mathrm{~kg} / \mathrm{m}^{3}$ fiber after 28 days of curing is $7.6 \%$ more when compared to the concrete samples with $2 \mathrm{~kg} / \mathrm{m}^{3}$ fiber reinforcement. An Increase in pressure strength with the increasing curing period is 
provided by filling the gaps between the aggregate grains of C-S-H gels formed by binder hydration and the increase in hardness of concrete samples. The most prominent feature of this is the increase in the UPV rates. The UPV rate in samples containing excess fiber is measured and found to be $30.4 \%$ more when compared to the samples with $2 \mathrm{~kg} / \mathrm{m}^{3}$ fiber reinforcement. Furthermore, consolidation of the concrete with its own weight, drying and evaporation of the water within may contribute to the development of hardening of the shotcrete sample.

\section{References}

[1] Choumanidis, D., Badogiannis, E., Nomikos, P., Sofianos, A. "Barcelona test for the evaluation of the mechanical properties of single and hybrid FRC, exposed to elevated temperature", Construction and Building Materials, 138, pp. 296-305, 2017. https://doi.org/10.1016/j.conbuildmat.2017.01.115

[2] Yan, X., Liu, L., Zhang, J., Li, Y., Wang, H. "Experimental Study on Basic Mechanical Properties of Steel Fiber-Reinforced Siliceous Wet Shotcrete", Advances in Materials Science and Engineering, 2018, Article ID 1637261, 2018.

https://doi.org/10.1155/2018/1637261

[3] Su, Y., Li, J., Wu, C., Wu, P., Li, Z-X. "Effects of steel fibres on dynamic strength of UHPC", Construction and Building Materials, 114, pp. 708-718, 2016.

https://doi.org/10.1016/j.conbuildmat.2016.04.007

[4] Bernard, E. S. "Correlations in the behaviour of fibre reinforced shotcrete beam and panel specimens", Materials and Structures, 35, pp. 156-164, 2002.

https://doi.org/10.1007/BF02533584

[5] Lee, J.-H., Kim, H.-H., Park, S.-K., Oh, R.-O., Kim, H.-D., Park, C.-G. "Mechanical Properties and Durability of Latex-Modified Fiber-Reinforced Concrete: A Tunnel Liner Application", Advances in Materials Science and Engineering, 2018, Article ID 2134873, 2018.

https://doi.org/10.1155/2018/2134873

[6] Kadam, S. B., Singh, Y., Li, B. "Strengthening of unreinforced masonry using welded wire mesh and micro-concrete - Behaviour under in-plane action", Construction and Building Materials, 54, pp. 247-257, 2014.

https://doi.org/10.1016/j.conbuildmat.2013.12.033

[7] Maidl, B., Dietrich, J. "Verification of Serviceability for Steel Fibre Reinforced Concrete in Tunnelling", Structural Engineering International, 2(2), pp. 114-117, 2018.

https://doi.org/10.2749/101686692780615941

[8] Song, P. S., Hwang, S., Sheu, B. C. "Strength properties of nylonand polypropylene-fiber-reinforced concretes", Cement and Concrete Research, 35(8), pp. 1546-1550, 2005.

https://doi.org/10.1016/j.cemconres.2004.06.033

[9] Armelin, H. S., Helene, P. "Physical and Mechanical Properties of Steel-Fiber Reinforced Dry-Mix Shotcrete", Materials Journal, 92(3), pp. 258-267, 1995.

https://doi.org/10.14359/1118

\section{Acknowledgment}

The author would like to express their sincere thanks and appreciation to Gümüşhane Koza Gold Enterprise, for their contributions and assistance in this study.

\section{Research data for this article}

All data generated or analyzed during this study are included in this published article. The author declare that there is no conflict of interest regarding the publication of this paper.

[10] Miao, B., Chern, J.-C., Yang, C.-A. "Influences of fiber content on properties of self-compacting steel fiber reinforced concrete", Journal of the Chinese Institute of Engineers, 26(4), pp. 523-530, 2011. https://doi.org/10.1080/02533839.2003.9670805

[11] Di Maida, P., Radi, E., Sciancalepore, C., Bondioli, F. "Pullout behavior of polyester macro-synthetic fibers treated with nanosilica", Construction and Building Materials, 82, pp. 39-44, 2015. https://doi.org/10.1016/j.conbuildmat.2015.02.047

[12] Yun, K.-K., Choi, P., Yeon, J. H. "Predicting Pumpability and Shootability of Crushed Aggregate Wet-Mix Shotcrete Based on Rheological Properties", Advances in Materials Science and Engineering, 2016, Article ID 9838213, 2016. https://doi.org/10.1155/2016/9838213

[13] Ercikdi, B., Y1lmaz, T., Külekci, G. "Strength and ultrasonic properties of cemented paste backfill", Ultrasonics, 54, pp. 195-204, 2014. https://doi.org/10.1016/j.ultras.2013.04.013

[14] ASTM "ASTM C597 - 16 Standard Test Method for Pulse Velocity Through", ASTM International, West Conshohocken, PA, USA, 2009. https://doi.org/10.1520/C0597-16

[15] Galaa, A. M., Thompson, B. D., Grabinsky, M. W., Bawden, W. F. "Characterizing stiffness development in hydrating mine backfill using ultrasonic wave measurements", Canadian Geotechnical Journal, 48(8), pp. 1174-1187, 2011.

https://doi.org/10.1139/t11-026

[16] Mahar, J. W., Parker, H. W., Wuellner, W. W. "Shotcrete practice in underground construction", U.S. Department of Transportation, Springfield, VA, USA, Rep. FRA-OR\&D 75-90, 1975.

[17] Yang, J.-M., Kim, J.-K., Yoo, D.-Y. "Performance of shotcrete containing amorphous fibers for tunnel applications", Tunnelling and Underground Space Technology, 64, pp. 85-94, 2017. https://doi.org/10.1016/j.tust.2017.01.012

[18] IAEA "Guidebook on non-destructive testing of concrete structures", Training Course Series No. 17, International Atomic Energy Agency, Vienna, Austria, 2002.

[19] Su, Y., Li, J., Wu, C., Wu, P., Li, Z.-X. "Effects of steel fibres on dynamic strength of UHPC", Construction and Building Materials, 114, pp. 708-718, 2016.

https://doi.org/10.1016/j.conbuildmat.2016.04.007 
[20] Cengiz, O., Turanli, L. "Comparative evaluation of steel mesh, steel fibre and high-performance polypropylene fibre reinforced shotcrete in panel test", Cement and Concrete Research, 34(8), pp. 13571364, 2004.

https://doi.org/10.1016/j.cemconres.2003.12.024

[21] Morgan, D. R., Heere, R., McAskill, N., Chan, C. "Comparative Evaluation of System Ductility of Mesh and Fibre Reinforced Shotcretes", presented at the Eighth International Conference on Shotcrete for Underground Support, Campos do Jordão, Brazil, April, 11-15, 1999.

[22] Bernard, E. S. "Measurement of post-cracking performance in fibre reinforced shotcrete", presented at Australian Shotcrete Conference, Sydney, Australia, Oct. 8-9, 1998.

[23] Chen, J., Zhao, P., Luo, Y., Deng, X., Liu, Q. "Damage of shotcrete under freeze-thaw loading", Journal of Civil Engineering and Management, 23(5), pp. 583-593, 2017.

https://doi.org/10.3846/13923730.2016.1210224

[24] Shabdin, M., Attari, N. K. A., Zargaran, M. "Experimental Study on Seismic Behavior of Unreinforced Masonry (URM) Brick Walls Strengthened in the Boundaries with Shotcrete", Journal of Earthquake Engineering, 2019.

https://doi.org/10.1080/13632469.2019.1577763
[25] Komurlu, E., Demir, S. "Determination of Direct Tensile Strength Values of Rock Materials by a New Test Method of Drilled Disc Tension", Periodica Polytechnica Civil Engineering, 64(1), pp. 33-41, 2020.

https://doi.org/10.3311/PPci.15004

[26] Ercikdi, B., Külekci, G., Yılmaz, T. "Utilization of granulated marble wastes and waste bricks as mineral admixture in cemented paste backfill of sulphide-rich tailings", Construction and Building Materials, 93, pp. 573-583, 2015.

https://doi.org/10.1016/j.conbuildmat.2015.06.042

[27] ASTM C666 Procedure A "Standard Test Method for Resistance of Concrete to Rapid Freezing and Thawing", In: Annual Book of ASTM Standards, American Society of Testing Material, West Conshohocken, PA, USA, 2009. 